\title{
CAUSES OF INFERTILITY AMONG COUPLES IN PRISHTINA 2000-2010
}

\author{
Sahadete Shala ${ }^{*}$, Gjergji Theodhosi ${ }^{2}$, Artan Simaku $^{3}$ \\ ${ }^{1 *}$ University Clinical Centre in Prishtina, Kosovo; \\ ${ }^{2}$ Orthodox Clinic, Tirana, Albania; \\ ${ }^{3}$ Institute of Public Health, Tirana, Albania;
}

"Corresponding author, Sahadete Shala, e-mail: drsahadete@gmail.com;

Received November 2019; Accepted December 2019; Published January 2020;

DOI: https://doi.org/10.31407/ijees10.107

\begin{abstract}
The prevalence of infertility has increased significantly in recent years. The global prevalence of infertility is reported to be $10 \%-15 \%$ affecting approximately $10 \%$ of couples. The purpose of the study was to explore the causes of infertility among couples who visited the University Clinical Centre in Prishtina, Kosovo during the period of 2000-2010. Primary infertility was found in 229 (71.1\%) couples and Secondary in 93 (28.9\%) ones. Of the causes of infertility were: female factors in $127(39.4 \%)$ of couples, male factors in 58 (18\%), combined factors in $99(30.7 \%)$ and unknown infertility in $38(11.8 \%)$ of couples. In reviews of infertile couples, study of male and female factors is important and mostly the couples mentioned more than one reasons as the infertility factor. Finally, preconception care and counseling are recommended to all those who are planning a pregnancy to avoid failure.
\end{abstract}

Key words: Infertility, factors, primary, secondary 